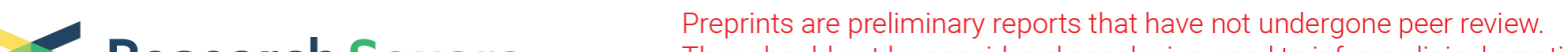 Research Square
or referenced not be considered conclusive, used to inform clinical practice,
os validated information.
}

\section{Comparison of Food Intakes of Diabetes, Hypertension and Heart Disease Patients with Clinical Symptoms of COVID-19 and Asymptomatic Controls.}

\section{Houra Mohseni}

MSc of Nutrition, School of Para-medicine Sciences, Ahvaz Jundishapur University of Medical Sciences, Ahvaz, Iran

Shirin Amini ( $\square$ amini-sh@shoushtarums.ac.ir)

Assistant professor of Nutrition, Department of Nutrition, Shoushtar Faculty of Medical Sciences,

Shoushtar, Iran

\section{Behnaz Abiri}

PhD in Nutrition, School of Para-medicine Sciences, Ahvaz Jundishapur University of Medical Sciences, Ahvaz, Iran

\section{Mojtaba Kalantar}

Assistant professor of Toxicology and Pharmacology, Shoushtar Faculty of Medical Sciences,

Shoushtar, Iran

\section{Short report}

Keywords: food intakes, symptoms, COVID-19, metabolic syndrome, nutritional supplements

Posted Date: October 5th, 2020

DOI: https://doi.org/10.21203/rs.3.rs-84142/v2

License: (c) (1) This work is licensed under a Creative Commons Attribution 4.0 International License. Read Full License 


\section{Abstract}

Background: In recent months, Coronavirus Disease 2019 (COVID-19) is a global health challenge. Nutrition is a key determining factor of health. In the present research, we assess and compare dietary food groups and nutrient supplements intake of diabetic, hypertensive and heart disease patients with clinical symptoms of COVID-19 and asymptomatic controls.

Methods: This retrospective case-control research was conducted on 98 patients with diabetes, hypertension, and/or heart disease that 37 of them were COVID-19 positive with clinical symptoms. Dietary intakes of participants were recorded using a food frequency questionnaire (FFQ), which was designed and validated for the Iranian population.

Results: $54 \%$ of all subjects had nutritional supplements consumption in the last 6 months, and there was no significant difference in the type of nutritional supplements between cases and controls. There was no significant difference in the median intake of food groups, in the last year, in metabolic syndrome patients with clinical symptoms of COVID-19 compared to controls. Crud OR shown, adequate consumption of any food groups was not associated with the occurrence of COVID-19.

Conclusion: While dietary intake and nutritional supplements may be excellent promise for preventing clinical symptoms of COVID-19, however, up to now, researches are not enough for recommending these supplements above the Recommended Dietary Allowances (RDA) for prevention and/or treatment of COVID-19.

\section{Background}

Recent months, Coronavirus Disease 2019 (COVID-19) is a global health challenge which leads to acute respiratory distress syndrome, respiratory and multiorgan failure, and increases mortality rate in metabolic syndrome (MetS) patients [1, 2]. Nutrition is a key determining factor of health [3]. A recent study suggested that malnutrition can impact on immune cell metabolism and function [4]. Nearly $33.6 \%$ of adults population in Iran are suffering from MetS which is possibly caused by increased intake of the Western diet (WD) containing high amounts of saturated fat (HFD), refined carbohydrates and sugars, and low levels of fiber, unsaturated fats, and antioxidants $[5,6]$ Modern diet seems an important factor influencing the severity symptoms of COVID-19, through damaging the immune system $[7,8]$.

A recent systematic review proposed nutrients with probable antivirus properties [9]. However, up to now, no research has evaluated the history of food intake and incidence of COVID-19 infection. Patients with history of diabetes, hypertension, and heart disease have a worse prognosis and are at greater risk for more severe symptoms and mortality from COVID-19.

\section{Methods}

\section{Study design and participants}


We conducted a retrospective case-control research on 98 patients with diabetes, hypertension, and/or heart disease that 37 of them were COVID-19 positive with clinical symptoms. A total of 37 COVID-19 positive patients that recurred, had laboratory-confirmed SARS-CoV-2 (Severe acute respiratory syndrome coronavirus 2) infection diagnosis by RTePCR (Reverse Transcriptase Polymerase Chain Reaction) of nasopharyngeal swabs, and hospitalized and/or referring to the outpatient clinic of Khatam Al-Anbia Hospital, in Shoushtar city, Khuzestan province, in Iran, between June and Aug 2020. We compared the case group with 61 MetS patients exposed to SARS-CoV-2 and asymptotic (control group).

Control group were selected from physicians, nurses, and staff working in hospitals, and medical centers and also, near family members of infected patients with SARS-CoV-2 that encountered the virus but no observed clinical symptoms of COVID-19.

The Medical Ethics Committee at the Shoushtar faculty of medical science approved the research protocol according to the guidelines of the 2013 Helsinki Declaration (Registration No: IR.SHOUSHTAR.REC.1399.015).

Dietary intakes of participants were recorded using a food frequency questionnaire (FFQ), which was designed and validated for the Iranian population [10]. The frequency of food groups (based on the food pyramid) that consumed, in the last year, asked in forms of daily, weekly, monthly, yearly, or never and then converted and reported to the unit per day.

\section{Statistical analyses}

The datasets used and analyzed during the current study are available from the corresponding author upon the reasonable request. Categorical variables were reported as frequency rates and percentages (\%). Categorical variables compared using chi-squared test. Continuous data with normal or non-normal distribution were described using mean \pm standard deviation (mean \pm SD) or median (25th, and 75th percentile), respectively. Mann-Whitney U Test and Independent t-test used to compare continuous variables. Logistic regression was used to estimate the strength of the association between daily food groups and the odds ratios (ORs) of COVID-19. All statistical analyses were performed using SPSS (Statistical Package for the Social Sciences) version 17.0 (SPSS Inc, Chicago, IL, USA). Two-sided Pvalues with $P<0.05$ were considered statistically significant.

\section{Results}

In our study, case and control groups were matched in terms of body mass index (BMI), gender, and age. There was no significant difference in the characteristics of participants between the two groups. The median BMI of all participants was $26.46 .54 \%$ of all subjects had a consumption of nutritional supplements in the last 6 months, and there was no significant difference in the type of nutritional supplements between cases and controls. Table 1 demonstrates a comparison of daily food groups intake between two groups. Unexpectedly, we observed no significant difference in the median intake of 
food groups, in the last year, in MetS patients with clinical symptoms of COVID-19 compared to controls. The results of the logistic regression models about the relation between daily food groups intake and the occurrence of COVID-19, with OR and 95\% confidence intervals (CI), illustrated in Table 2. Crud OR shown, adequate consumption of any food group was not associated with the occurrence of COVID-19. 
Table 1

Comparison of basic characteristics, anthropometric measures and daily food groups intake (per unit) between cases and controls.

\begin{tabular}{|c|c|c|c|}
\hline Characteristics & $\begin{array}{l}\text { Asymptotic group } \\
\text { (Controls) } \\
\mathrm{n}=61\end{array}$ & $\begin{array}{l}\text { COVID-19 positive with } \\
\text { clinical symptoms } \\
\text { (Cases) } \\
\mathrm{n}=37\end{array}$ & $\begin{array}{l}P \\
\text { value }\end{array}$ \\
\hline Age (years) ${ }^{f}$ & $33.62(22,59)$ & $32.86(17,51)$ & 0.60 \\
\hline Weight $(\mathrm{kg})^{£}$ & $73.43(43.5,110.5)$ & $69.78(50.5,95.0)$ & 0.20 \\
\hline Height $(\mathrm{cm})^{€}$ & $166.97 \pm 9.29$ & $164.47 \pm 8.27$ & 0.17 \\
\hline BMI $\left(\mathrm{kg} / \mathrm{m}^{2}\right)^{f}$ & $26.27(16.94,39.06)$ & $26.05(15.40,34.89)$ & 0.80 \\
\hline Gender \# & & & 0.59 \\
\hline Female, (n (\% & $38(62.3)$ & $25(67.6)$ & \\
\hline Male, (n (\% & $23(37.7)$ & $12(32.4)$ & \\
\hline Physical activity\# & & & 0.82 \\
\hline Active & $6(9.8)$ & $3(8.1)$ & \\
\hline Minimally active & $34(55.8)$ & $23(62.2)$ & \\
\hline Inactive & $21(34.4)$ & $11(29.7)$ & \\
\hline Educational level n (\%) \# & & & 0.17 \\
\hline Elementary & $8(13.1)$ & $10(27)$ & \\
\hline Diploma & $16(26.2)$ & $6(16.2)$ & \\
\hline College & $37(60.7)$ & $21(56.8)$ & \\
\hline Income $(n, \%){ }^{\#}$ & & & 0.24 \\
\hline Upper-middle & $15(24.6)$ & $4(10.8)$ & \\
\hline Middle & $26(42.6)$ & $18(48.6)$ & \\
\hline
\end{tabular}

$€$ Data are illustrated as mean \pm standard deviation (mean \pm SD), and analyzed by Independent $t$-test.

${ }^{\text {ED }}$ ata are illustrated as median (25th, 75th percentiles) and analyzed by Mann-Whitney Utest.

\# Data are illustrated as $\mathrm{n}(\%)$, and analyzed by chi-square.

$P$-value $<0.05$ was considered significant. BMl: body mass index 


\begin{tabular}{|c|c|c|c|}
\hline Characteristics & $\begin{array}{l}\text { Asymptotic group } \\
\text { (Controls) } \\
n=61\end{array}$ & $\begin{array}{l}\text { COVID-19 positive with } \\
\text { clinical symptoms } \\
\text { (Cases) } \\
\mathrm{n}=37\end{array}$ & $\begin{array}{l}P \\
\text { value }\end{array}$ \\
\hline Lower-middle & $20(32.8)$ & $15(40.6)$ & \\
\hline Marital status" & & & 0.59 \\
\hline Married & $54(88.5)$ & $34(91.9)$ & \\
\hline Single & $7(11.5)$ & $3(8.1)$ & \\
\hline History of smoking ${ }^{\#}$ & & & 0.09 \\
\hline No & $46(75.41)$ & 33(89.2) & \\
\hline Yes & $15(24.59)$ & $4(10.8)$ & \\
\hline $\begin{array}{l}\text { Nutritional supplement consumption in } \\
\text { last } 6 \text { month\#" }\end{array}$ & & & 0.28 \\
\hline No & $29(47.5)$ & $17(45.9)$ & \\
\hline \multicolumn{4}{|l|}{ Yes } \\
\hline Vitamin C & $3(4.9)$ & $4(10.8)$ & \\
\hline Iron & $2(3.3)$ & $4(10.8)$ & \\
\hline Vitamin D3 & 21(34.4) & 11(29.7) & \\
\hline Multivitamin & $6(9.9)$ & $1(2.8)$ & \\
\hline \multicolumn{4}{|l|}{ Daily food intake (per unit) ${ }^{£}$} \\
\hline Bread & $2.84(1.0,7.0)$ & $2.50(1.0,7.0)$ & 0.24 \\
\hline Rice & $1.54(0.14,4.6)$ & $1.59(0.14,4.50)$ & 0.76 \\
\hline Pasta & $0.21(0.01,0.90)$ & $0.11(0.01,0.40)$ & 0.07 \\
\hline Cheese & $1.3(0.0,4.5)$ & $1.00(0.07,3.0)$ & 0.15 \\
\hline Yogurt & $0.50(0.0,2.0)$ & $0.56(0.0,3.0)$ & 0.61 \\
\hline \multicolumn{4}{|c|}{$€^{€}$ Data are illustrated as mean \pm standard deviation (mean \pm SD), and analyzed by Independent $t$-test. } \\
\hline \multicolumn{4}{|c|}{ 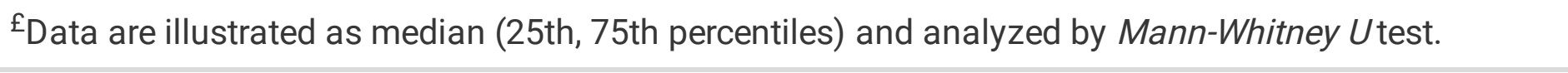 } \\
\hline \multicolumn{4}{|c|}{ \# Data are illustrated as $\mathrm{n}(\%)$, and analyzed by chi-square. } \\
\hline$P$-value $<0.05$ was considered significan & BMI: body mass ind & & \\
\hline
\end{tabular}




\begin{tabular}{|c|c|c|c|}
\hline Characteristics & $\begin{array}{l}\text { Asymptotic group } \\
\text { (Controls) } \\
n=61\end{array}$ & $\begin{array}{l}\text { COVID-19 positive with } \\
\text { clinical symptoms } \\
\text { (Cases) } \\
\mathrm{n}=37\end{array}$ & $\begin{array}{l}P \\
\text { value }\end{array}$ \\
\hline Dough & $0.39(0.0,2.0)$ & $0.34(0.0,2.0)$ & 0.60 \\
\hline Milk & $1.26(0.0,3.0)$ & $1.40(0.0,2.0)$ & 0.23 \\
\hline Ice cream & $0.20(0.0,3.0)$ & $0.23(0.0,3.0)$ & 0.74 \\
\hline Chicken & $0.60(0.0,2.0)$ & $0.54(0.0,2.0)$ & 0.44 \\
\hline Fish & $0.23(0.0,0.85)$ & $0.33(0.0,0.85)$ & 0.10 \\
\hline Red Meat & $0.67(0.0,4.0)$ & $0.54(0.0,4.0)$ & 0.30 \\
\hline legumes & $0.28(0.0,2.0)$ & $0.27(0.0,1.0)$ & 0.81 \\
\hline Egg & $0.44(0.0,2.0)$ & $0.45(0.0,2.0)$ & 0.89 \\
\hline Fruit & $1.85(0.0,4.0)$ & $1.7(0.07,4.0)$ & 0.71 \\
\hline Vegetables & $1.40(0.0,5.50)$ & $1.12(0.00,5.50)$ & 0.38 \\
\hline \multicolumn{4}{|c|}{${ }^{€}$ Data are illustrated as mean \pm standard deviation (mean $\pm S D$ ), and analyzed by Independent $t$-test. } \\
\hline \multicolumn{4}{|c|}{ EData are illustrated as median (25th, 75th percentiles) and analyzed by Mann-Whitney Utest. } \\
\hline \multicolumn{4}{|c|}{ \# Data are illustrated as $\mathrm{n}(\%)$, and analyzed by chi-square. } \\
\hline$P$-value $<0.05 \mathrm{w}$ & Ml: body mass ir & & \\
\hline
\end{tabular}


Table 2

Occurrence clinical symptoms of COVID19 by intakes of food groups, using Odds ratios (ORs) $\S$ and $95 \%$ confidence intervals (Cls).

\begin{tabular}{|lllll|}
\hline Daily food intake & Crude OR & P-value & Adjusted OR & P-value \\
\hline Bread & $0.82(0.60,1.13)$ & 0.24 & $0.82(0.59,1.12)$ & 0.22 \\
\hline Rice & $1.05(0.73,1.53)$ & 0.76 & $1.10(0.75,1.59)$ & 0.61 \\
\hline Pasta & $0.01(0.0,1.40)$ & 0.08 & $0.01(0.0,1.37)$ & 0.09 \\
\hline Cheese & $1.59(0.73,3.43)$ & 0.23 & $1.50(0.69,3.26)$ & 0.30 \\
\hline Yogurt & $1.20(0.58,2.50)$ & 0.60 & $1.08(50,2.37)$ & 0.83 \\
\hline Dough & $0.80(0.34,1.86)$ & 0.61 & $0.80(0.34,1.89)$ & 0.62 \\
\hline Milk & $0.74(0.49,1.23)$ & 0.16 & $0.73(0.48,1.12)$ & 0.15 \\
\hline Ice cream & $1.14(0.50,2.61)$ & 0.74 & $1.14(0.50,2.62)$ & 0.74 \\
\hline Chicken & $0.65(0.22,1.89)$ & 0.43 & $0.62(0.21,1.82)$ & 0.38 \\
\hline Fish & $3.23(0.79,13.23)$ & 0.10 & $2.91(0.70,12.05)$ & 0.13 \\
\hline Red Meat & $0.66(0.30,1.46)$ & 0.31 & $076(0.30,1.88)$ & 0.55 \\
\hline legumes & $0.84(0.21,3.27)$ & 0.81 & $0.83(0.21,1.32)$ & 0.80 \\
\hline Egg & $1.07(0.37,3.07)$ & 0.89 & $1.31(0.40,4.22)$ & 0.64 \\
\hline Fruit & $0.94(0.69,1.28)$ & 0.70 & $0.91(0.95,1.26)$ & 0.57 \\
\hline Vegetables & $0.88(0.65,1.17)$ & 0.38 & $0.87(0.65,1.16)$ & 0.36 \\
\hline SOR calculated by logistic regression model. Model 1 Adjusted for energy intake, BMl and & \\
\hline consumption of nutritional supplements. & & & \\
\hline
\end{tabular}

\section{Discussion}

Our study is the first case-control research to compare dietary food intakes in MetS patients with clinical symptoms of COVID-19 and controls. The present data support that no specific food groups or nutritional supplement have an effect on the occurrence of COVID-19. However, a previously published opinion suggested mechanisms involved in the potential role of diet and nutrients in the prevention of COVID-19 via the strengthening of the immune system and reducing inflammation and oxidative stress $[11,12]$. The mechanisms likely underlie such beneficial roles are not completely understood and other unknown factors may have interfered.

\section{Conclusion}


While dietary intake and nutritional supplements may offer excellent promise for preventing clinical symptoms of COVID-19, however, up to now, researches are not enough for recommending these supplements above the Recommended Dietary Allowances (RDA) for prevention and/or treatment of COVID-19. SARS-CoV-2 is a new virus with unknown function, hence strong researches are required to confirm these suggestions and provide hypothesis and opinions.

\section{List Of Abbrivation}

COVID-19: Coronavirus Disease 2019

FFQ: food frequency questionnaire

MetS: metabolic syndrome

WD: Western Diet

HFD: High Fat Diet

SARS-CoV-2

RTePCR: Reverse Transcriptase Polymerase Chain Reaction

ORs: odds ratios

RDA: Recommended Dietary Allowances

\section{Declarations}

\section{Ethics approval}

Medical Research Ethics Committee at the Shoushtar Faculty of Medical Sciences approved the study (Registration No: IR.SHOUSHTAR.REC.1399.015).

\section{Consent to participate}

All participate signed a consent form

\section{Availability of data and material}

The datasets generated and/or analyzed during the current study are not publicly available but are available from the corresponding author on a reasonable request.

\section{Competing interests}

The authors declare no conflict of interest. 


\section{Funding}

This research financially supported by the Vice-Chancellor for Research Affairs of Shoushtar faculty of Medical Sciences, Shoushtar, Iran. (Grant number: 99000020).

\section{Authors'contributions}

$\mathrm{H}$ Mohseni and S Amini contributed in the conception and design, analysis of data and interpretation of the research, also, in the writing and revision of the manuscript. B Abiri and M Kalantar contributed to the critical revision of the manuscript. All authors approved the final version of the manuscript before submitting it.

\section{Acknowledgements}

The authors wish to thank all participants and the personnel of Khatam Al-Anbia Hospital. Special thanks to Vice-Chancellor for Research Affairs of Shoushtar faculty of Medical Sciences which financially supported the project.

\section{References}

1. Phelan AL, Katz R, Gostin LO. The novel coronavirus originating in Wuhan, China: challenges for global health governance. Jama. 2020;323(8):709-10.

2. Wang C, Horby PW, Hayden FG, Gao GF. A novel coronavirus outbreak of global health concern. The Lancet. 2020;395(10223):470-3.

3. Covinsky K, Katz M. Supplemental Nutrition Assistance Program-Do Not Take the Food Out of Patients' Mouths. JAMA Internal Medicine. 2020;180(4):605-6.

4. Alwarawrah Y, Kiernan K, Maclver NJ. Changes in nutritional status impact immune cell metabolism and function. Frontiers in immunology. 2018;9:1055.

5. Farmanfarma KK, Kaykhaei MA, Adineh HA, Mohammadi M, Dabiri S, Ansari-moghaddam A. Prevalence of metabolic syndrome in Iran: A meta-analysis of 69 studies. Diabetes \& Metabolic Syndrome: Clinical Research \& Reviews. 2019;13(1):792-9.

6. Cordain L, Eaton SB, Sebastian A, Mann N, Lindeberg S, Watkins BA, et al. Origins and evolution of the Western diet: health implications for the 21 st century. The American journal of clinical nutrition. 2005;81(2):341-54

7. Laviano A, Koverech A, Zanetti M. Nutrition support in the time of SARS-CoV-2 (COVID-19). Nutrition (Burbank, Los Angeles County, Calif). 2020;74:110834.

8. Myles IA. Fast food fever: reviewing the impacts of the Western diet on immunity. Nutrition journal. 2014;13(1):1-17.

9. Zhang L, Liu Y. Potential interventions for novel coronavirus in China: A systematic review. Journal of medical virology. 2020;92(5):479-90. 
10. Mirmiran P, Esfahani FH, Mehrabi Y, Hedayati M, Azizi F. Reliability and relative validity of an FFQ for nutrients in the Tehran lipid and glucose study. Public health nutrition. 2010;13(5):654-62.

11. Calder PC. Nutrition, immunity and COVID-19. BMJ Nutrition, Prevention \&amp; Health. 2020:bmjnph2020-000085.

12. Iddir M, Brito A, Dingeo G, Fernandez Del Campo SS, Samouda H, La Frano MR, et al. Strengthening the Immune System and Reducing Inflammation and Oxidative Stress through Diet and Nutrition: Considerations during the COVID-19 Crisis. Nutrients. 2020;12(6):1562. 